\title{
Análisis de nuestras prácticas docentes
}

Sofía de los Milagros Alí

Profesora Adjunta. Cátedra Odontología Social y Comunitaria. Facultad de Odontología. UNNE

\section{Roxana Lilian Blanco}

Auxiliar Docente. Cátedra Odontología Social y Comunitaria. Facultad de Odontología. UNNE

\section{María Alejandra Meana} Auxiliar Docente. Cátedra Odontología Social y Comunitaria. Facultad de Odontología. UNNE

\section{Alina Noelia Peláez}

Auxiliar Docente. Cátedra Metodología de la Investigación. Facultad de Odontología. UNNE.

\section{María Natalia Rosende}

Jefe de Trabajos Prácticos. Cátedra de Psicología del niño, adolescente y el adulto. Facultad de Odontología. UNNE.

\section{Resumen}

La práctica docente es proceso continuo, que apunta a transformaciones dinámicas que deben responder a las inquietudes y necesidades particulares de cada uno y a las que sólo se llega cuestionando la propia práctica y reflexionando desde ella. Cuestionarnos los saberes en los que se fundamenta nuestra actividad, posibilita la estructuración de nuevas estrategias para la acción.

El análisis de nuestra práctica, nos permite revelar concepciones y valores acerca de la enseñanza, aprender de las experiencias y prácticas de los demás y por qué no, aventurarnos a transformar nuestra práctica docente.

\section{Palabras Claves}

Reflexión de nuestra práctica; Actividad educacional; Aprender a enseñar

\section{Abstract}

Teaching practice is a continuous process, which aims to dynamic changes that must respond to the concerns and needs of each and to which only comes into question the practice and reflecting from it. Questioning the knowledge on which our activity is based, it enables the structuring of new strategies for action.

The analysis of our practice allows us to reveal conceptions and values about teaching, learning from the experiences and practices of 
others and why not venture to transform our teaching practice.

\section{Keywords}

Reflection of our practice, Educational activity, Learning to teach

\section{Resumo}

Prática de ensino é um processo contínuo, que visa a mudanças dinâmicas que devem responder às preocupações e necessidades de cada um e à qual só entra em questão a prática e refletindo a partir dele. Questionando o conhecimento no qual a nossa actividade baseia-se, permite a estruturação de novas estratégias de ação.

A análise da nossa prática nos permite revelar concepções e valores sobre o ensino, aprendendo com as experiências e práticas dos outros e por isso não se aventurar para transformar nossa prática docente.

\section{Palavras Chaves}

Reflexão da nossa prática; Atividade educacional; Aprender a ensinar

\section{Introducción}

Se espera mucho de las prácticas docentes, ya que en nuestras manos está el de formar futuros profesionales, por tal motivo es necesario hacer un análisis de nuestras prácticas. La formación del docente no es posible sólo desde una concepción instrumental, que centra la atención en la formación de conocimientos y habilidades para el ejercicio de la docencia.

Coincidentemente con González Maura' la formación del profesor como modelo educativo de los estudiantes exige que se la haga desde una concepción humanista en la cual estudiantes y profesores se asumen como sujetos de enseñanza y aprendizaje, entendida como desarrollo profesional ${ }^{2}$.

En todo proceso de aprender a enseñar confluyen experiencias, conocimientos, situaciones, que se producen en contextos diferentes e igualmente válidos, en nuestro caso, la universidad y las instituciones educativas que brindan sus espacios y recursos para que nuestros estudiantes lleven a cabo sus prácticas; por tanto, se hace necesaria una cooperación más estrecha entre ambos contextos para que los sujetos implicados: estudiantes y profesores, aprendan continuamente e investiguen y construyan el conocimiento sobre la enseñanza.

Visto así, el aprender a enseñar, como un proceso continuo apunta a transformaciones dinámicas en las prácticas educativas de los docentes. Transformaciones que deben responder a las inquietudes y necesidades particulares de cada uno y a las que sólo se llega cuestionando la propia práctica, reflexionando desde ella.

Realizar el análisis de nuestras prácticas, permitió ver más allá de nuestras asignaturas y muros, revelar nuestras concepciones y valores acerca de la enseñanza, aprender de las experiencias y prácticas de los demás y por qué no, aventurarnos a transformar nuestra práctica docente. No es sencillo, por un lado se arraiga nuestra tradición educativa y por el otro, animarnos a evolucionar en lo tradicional y a poner en práctica nuestras habilidades docentes, lo cual demanda de procesos reflexivos sobre nuestro quehacer que no acostumbramos desarrollar. Requiere que desarrollemos la capacidad de cuestionar el conocimiento a la luz de la experiencia para afirmarlo o hacer nuevas elaboraciones. Igualmente, exige que nos observemos a nosotros mismos y nos interroguemos sobre nuestros pensamientos $y$ acciones.

Por lo cual es preciso detenernos y evaluar ciertas características que nos demanda la práctica docente, como por ejemplo; saber trabajar en equipo, desarrollar nuevas estrategias, favorecer aprendizajes relevantes, tener mejores competencias didácticas, presentar mayor dominio de los contenidos de aprendizaje, entre otras.

\section{Desarrollo}

Consideramos que la formación docente entendido como desarrollo profesional tiene lugar a lo largo de toda la vida y comprende tanto a la formación y desarrollo de cualidades cognitivas, motivacionales, como afectivas. Es decir, no es sólo el perfeccionamiento de conocimientos y habilidades profesionales, sino también de vivencias, motivaciones $y$ valores que le permitan una actuación profesional ética y responsable. En este proceso se pueden diferenciar tres mo- 
mentos: la formación inicial, la formación del profesorado novel y la formación del docente experimentado 3 .

Teniendo en cuenta los términos antes mencionados, son empleados, a su vez, de diferente modo por los diversos autores para referirse a los mismos fenómenos"4. En dicho trabajo se puede entender el desarrollo profesional como: "un proceso que afecta a la dimensión personalprofesional del docente como a la institucionalorganizativa"'5. Se caracteriza por ser un continuo, social, sistemático, colectivo y que incide en las dimensiones pedagógicas, personales y sociales del docente.

Pensamos que la formación docente constituye el eje central de cualquier sistema educativo. En tanto implica la formación de nosotros los formadores, los cuales tenemos en nuestras manos la educación de los jóvenes. Es así, que consideramos que el valor otorgado a la Formación Docente, implica considerar a ésta como el centro de cualquier transformación educativa, si en verdad aspiramos a modificaciones de fondo y no de simple forma.

Desde ese lugar pensamos que, la práctica docente constituye el eje vertebrado de la Formación Docente; lo cual es el resultado de una visión teórico - práctica - metodológica que considera a las mismas desde un lugar diferente.

La práctica educativa de los docentes es una actividad dinámica, reflexiva, que comprende los acontecimientos ocurridos en la interacción entre docentes y alumnos. No se limita al concepto de docencia, es decir, a los procesos educativos que tienen lugar dentro del salón de clases, incluye la intervención pedagógica ocurrida antes y después de los procesos interactivos en el aula ${ }^{6}$.

En este sentido, en primer lugar deberíamos distinguir entre práctica de la enseñanza y práctica docente. La primera implica centrar la acción docente en la complejidad del aula pero, al limitar la tarea sólo a ese espacio, quedan afuera diferentes actividades, situaciones, relaciones, circulación del poder, que constituyen y conforman la tarea docente. En cambio la noción de práctica docente encuadra la tarea en una red de relaciones y construcción permanente que excede el ámbito áulico. Comprendiendo que el desempeño del rol profesional, va mucho más allá de la tarea de enseñar y que se deben tener en cuenta las condiciones contextuales e institucionales que hacen al accionar educativo.

Por tal motivo consideramos que, las prácticas docentes se constituyen en la propia trayectoria del sujeto a partir de una trama compleja de pensamientos, percepciones, representaciones explicables históricas, culturales y sociales ${ }^{7}$.

Es así que comprendimos, que formarse en el ámbito de la reflexión y el análisis de la práctica docente, no es tarea fácil, implica saber observar, tener referentes teóricos sobre los asuntos a observar, valorar la construcción de diversos conocimientos y evaluar el logro de los objetivos educativos. Pero en realidad existe un problema importante, el cual radica en que muchos docentes estamos "acostumbrados" a no enseñar más que lo que nos enseñaron y de la misma forma en la que lo hicieron. Si la actitud epistémica de hacernos preguntas, más que buscar respuestas estuviera incorporada en nuestra subjetividad, sería factible interpelar los objetos de conocimiento y al conocimiento mismo como otro objeto más de conocimiento. Consideramos que es preciso provocar el pliegue que permita una nueva praxis informada $y$ crítica, para sustentar intervenciones didácticas que provoquen la ruptura del "círculo vicioso" 8 .

Las principales diferencias entre distintos docentes está dada por el tipo de relación que cada uno de ellos establece con el saber, que se manifiesta en su dominio de la materia y el significado que da al contenido propuesto en su enseñanza, la forma de situarse y de situar al alumno con relación a dicho saber, los marcos de referencia que sugiere o impone y los tiempos de construcción conceptual que otorga o niega. Esta asimetría tiene grados que pueden llegar a un punto extremo donde no ocurra comunicación en el aula.

En la elaboración conjunta de un conocimiento, el docente regula el ritmo y tiempos de construcción, que no siempre contemplan las posibilidades del alumno, haciendo valer su autoridad tanto académica como funcional. Si bien el docente personifica el conocimiento realmente enseñado, sus fuentes previas de validación no siempre se originan en el conocimiento científico actualizado. Muchas veces la rutina de la docencia hace que tome sólo sus experiencias 
REVISTA FACULTAD DE ODONTOLOGÍA

ISSN No 1668-7280 - Vol. IX No 1 - 2016

46
INVESTIGACIÓN

Cardozo - González - Pérez - Vaculik - Sanz previas como criterio de validez, tanto las referidas al contenido disciplinar como las relacionadas con el conocimiento pedagógico didáctico correspondiente a la enseñanza de determinada asignatura y al posible aprendizaje, 10 .

"formarse es transformarse en el contacto con la realidad, y en el transcurso de la formación volverse capaz de administrar uno mismo su formación""I.

\section{Conclusión}

Si bien, guiamos, orientamos y acompañamos a nuestros alumnos en el camino del aprendizaje, debemos reconocer que nos falta incorporar, una gran cantidad de requisitos indispensables para poder desarrollar una buena práctica docente. Nuestra tarea es muy compleja, además de ir variando según diferentes factores de índole político- social. Hasta hace unos años pensábamos que la educación debería proveer al alumno de una gran masa de conocimientos, sin importar la estrategia empleada. Pero hoy, podemos ver que no debe ser así, que se debe tener en cuenta una serie de factores que hacen a nuestra pro-

\section{Bibliografía}

I. González Maura V. "El diario como instrumento de diagnóstico y estimulación del desarrollo profesional del profesorado". En: Revista Iberoamericana de Educación. 2006; 2 (82). Versión digital. [citado 18 de mayo 2016]. Disponible en: www.oei.es

2. Imbernón, F. La formación y el desarrollo profesional del profesorado. Hacia una nueva cultura profesional. Graó. Barcelona; 1998.

3. Vivas, M; Becerra, G. Y Diaz, D. "La formación del profesorado novel en el Dpto. de Pedagogía de la Universidad de los Andes Táchira. Rev. Electrónica de Investigación Educativa. 2005 [citado 20 de mayo 2016] Disponible en:http//redie.uabc.mx/vol7nol/ contenido-vivas.html

4. Medina Moya, J. La Profesión Docente y la construcción del conocimiento profesional. Editorial Magisterio del Río de la Plata. Buenos Aires; 2006.

5. De Rivas T. "Referentes en la socialización profesional: su impacto en la enseñanza". Ponencia en la Cuadragésimo sexta Asamblea Mundial ICET. La formación de profesores y los desafíos del cambio. Alternativas de cambio. Santiago de Chile. 200I.

6. García Cabrero B; Loredo Enríquez J; Carranza Peña, G. Análisis de la práctica educativa de los docentes: pensamiento, interacción y reflexión. Rev. electrónica fesión docente y no es solo limitarnos a transmitir conocimientos. Consideramos, que todos y cada uno de nosotros, debiéramos hacer una reflexión crítica sobre nuestras prácticas. Cuestionarnos los saberes en los que se fundamenta nuestra actividad, de manera tal de posibilitar la estructuración de nuevas estrategias para la acción. Asimismo pudimos identificar las acciones que conforman nuestra práctica, la intencionalidad y los intereses que se generan tanto en nosotros como en los alumnos. Igualmente el análisis de nuestra práctica, nos ha permitido ver más allá de nuestras asignaturas y muros, revelar nuestras concepciones y valores acerca de la enseñanza, aprender de las experiencias y prácticas de los demás y por qué no, aventurarnos a transformar nuestra práctica docente.

Todos deberíamos involucrarnos verdaderamente en este proceso de formación docente, de manera tal, que la adquisición de conocimientos y el desarrollo de habilidades mejore nuestras prácticas.

de investigación educativa, 2008. [citado 18 de mayo 2016] Disponible en:http://www.scielo.org.mx/scielo. php?script=sci_arttext\&pid=SI $607404 \mid 20080003000$ 06\&lng=es\&tlng=es.

7. Pievi, N., Bravin, C. Documento metodológico orientador para la investigación educativa. Ia ed. Buenos Aires: Ministerio de Educación de la Nación; 2009.

8. Gorodokin, I. "La formación docente y su relación con la epistemología”. Rev Iberoamericana de Educación. 2009 [citado 2 de mayo 2016] Disponible en: http:// www.rieoei.org/deloslectores/ I 164Gorodokin.pdf

9. De Longhi, A "El discurso del profesor y del alumno: análisis didáctico en clases de ciencias". Investigación Didáctica. Enseñanza de las Ciencias. 2000. [citado 10 de mayo2016]Disponibleen:http://www.raco.cat/ index.php/ensenanza/article/viewFile/2 I658/2I492

10. Kane, R.; Sandretto, S., Y Heath, C. Telling half the story: A critical review of research on the teaching beliefs and practices of university academics. Review of Education Research, 2002, 72 (2).

II. Ferry, G. "El trayecto de la formación. Los enseñantes entre la teoría y la práctica”. México: Editorial Paidós; 1990. 